\title{
CARACTERIZAÇÃO ANATÔMICA DA MADEIRA DE Eucalyptus benthamii Maiden et Cambage
}

\section{WOOD ANATOMIC CHARACTERIZATION OF Eucalyptus benthamii Maiden et Cambage}

\author{
Silvana Nisgoski ${ }^{1} \quad$ Graciela I. B. de Muñiz ${ }^{2} \quad$ Umberto Klock $^{3}$
}

\section{RESUMO}

O presente trabalho trata da descrição dos caracteres gerais e microscópicos da madeira de Eucalyptus benthamii Maiden et Cambage, sendo fornecidas fotomicrografias e fotografias em microscópio eletrônico. Foram encontrados poros em arranjo diagonal, característico do gênero; parênquima vasicêntrico e vasicêntrico confluente; raios homogêneos; fibras libriformes não septadas, e máculas medulares ocasionais. A porcentagem de elementos constituintes foi comparada com outras espécies da família Myrtaceae e as fibras e elementos vasculares avaliados em função da variação dentro da árvore.

Palavras-chave: Eucalyptus benthamii, madeira, anatomia.

\begin{abstract}
The wood anatomy of Eucalyptus benthamii Maiden et Cambage is described. Photomicrographs and photographs in electronic microscope are furnished. Vessels in a diagonal pattern, vasicentric parenchyma, homogeneous rays, libriform and not septated fibers, pith flecks occasionally were found. The percentage of constituent elements were compared with another species of the family Myrtaceae and the fibers and vascular elements were evaluated in function of the variation in the tree.
\end{abstract}

Key words: Eucalyptus benthamii, wood, anatomy.

\section{INTRODUÇÃO}

O eucalipto é uma essência florestal altamente integrada aos processos produtivos

1. Acadêmica do Curso de Pós-Graduação em Engenharia Florestal, M.Sc.UFPR. Escola de Florestas. CEP: 80035-010. Bairro Juvevê. Rua Bom Jesus, 650. Curitiba. PR.

2. Dr., Prof ${ }^{a}$. Titular do Departamento de Engenharia e Tecnologia Rurais/UFPR. Setor de Ciências Agrárias. Rua Bom Jesus, 650. Bairro Juvevê. Curitiba. PR.

3. MSc., Prof. Assistente do Departamento de Engenharia e Tecnologia Rurais/UFPR. Setor de Ciências Agrárias. Rua Bom Jesus, 650. Bairro Juvevê. Curitiba. PR. 
industriais e não industriais do Brasil, notadamente nas regiões Sul e Sudeste que formam o maior polo consumidor e exportador de madeira oriunda de plantios florestais (STAPE, 1996).

$\mathrm{Na}$ fase pré-incentivos fiscais as pesquisas sobre manejo das florestas de eucalipto foram abrangentes, mas em número naturalmente restrito. Durante a fase dos incentivos houve um aumento significativo, principalmente em relação ao sistema silvicultural de talhadia, buscando a otimização da produção volumétrica, ou da matéria seca, para atender aos processos que utilizam a madeira de forma massal, como lenha, carvão, chapas e celulose (STAPE, 1996).

Assim, as pesquisas de manejo de florestas de eucalipto para fins de produção de madeira para desdobro, iniciaram-se principalmente no final dos anos 70 e início dos anos 80, de forma que estão atualmente atingindo suas maturações e fornecendo informações relevantes para o manejo de eucalipto no sistema de alto fuste (STAPE, 1996).

O eucalipto conquistou importante posição na indústria de papel e celulose e na produção de carvão vegetal, e cada vez mais vem recebendo tratamento científico e conquistando ganhos de qualidade e produtividade através das técnicas de melhoramento genético e manejo florestal. Hoje, junto com o Pinus, o Eucalyptus é o gênero mais utilizado neste setor e de maior abundância em termos de florestas plantadas. Na atualidade, a busca de uso múltiplo das florestas e de melhor remuneração para a madeira tem incentivado o estabelecimento de estratégias por parte das empresas para a oferta de madeira serrada deste gênero (COSTA, 1996).

Num futuro próximo, quer seja pelas pressões ecológicas ou pela elevação do custo da madeira de origem de florestas naturais, ou ainda pelo constante aumento da consciência para a utilização de recursos florestais renováveis poderão ocorrer dificuldades para suprimento do setor moveleiro; deste modo, é cada vez mais premente a necessidade de se buscar novas alternativas de madeira para abastecimento das indústrias do setor (COSTA, 1996).

Assim, novas espécies de eucalipto e outras essências devem ser pesquisadas, avaliando-se seu potencial para os mais diversos fins, e introduzidas de acordo com cada local e também características próprias da árvore, as quais conferem maior resistência a geadas e outros fatores ambientais, além de qualidades referentes à madeira.

O Eucalyptus benthamii Maiden et Cambage, é originário da Austrália, derivando da cidade de Camden, perto da qual poucas espécies de pequeno diâmetro ainda existem. A árvore é moderadamente alta, atingindo $36 \mathrm{~m}$ e diâmetros de $50 \mathrm{~cm}$.

Tem uma distribuição limitada na costa leste de New South Wales. A maior ocorrência é no sudoeste de Sydney nas planícies de Nepean River e seus afluentes, especialmente aquelas submergidas no grande Warragamba Dam. Em adição há uma pequena área em Dorrigo Plateau.

O clima da localização sul é quente e úmido, com 4 a 10 geadas por ano, sendo a média anual de chuvas de 720 a $890 \mathrm{~mm}$. Para a localização nordeste as temperaturas do verão são comparáveis, mas o inverno é mais frio, com 30 a 40 geadas por ano. Muitas chuvas, em torno de $2.030 \mathrm{~mm}$ por ano e o mês mais seco tem aproximadamente $80 \mathrm{~mm}$ de chuva.

Este eucalipto prefere planícies de rios ou ladeiras brandas de países adjacentes. Os solos são moderadamente bons, aluviais, com qualidade agrícola, frequentemente com argila numa 
profundidade de 0,5 a $1 \mathrm{~m}$.

A casca persistente é fina, compacta e tende a formar pequenas tiras longitudinais as quais são aderentes apenas em parte. Folhas velhas opostas, sésseis, os primeiros dois a quatro pares elípticos a ovais; glândulas proeminentes espalhadas na folha e conspícuas no pecíolo. Folhas jovens opostas, sésseis, largamente oblongo ovadas a ovadas, subglaucas, textura moderadamente fina. Folhas intermediárias opostas a subopostas, sésseis ou com pequena haste, lanceoladas; verdes, textura moderadamente fina. Folhas adultas alternas, longas hastes, lanceoladas; verdes, algumas com textura fina.

Inflorescência axilar, 4-7 flores, pedúnculos com 0,5 cm de comprimento, pedicelos com 0,25 $\mathrm{cm}$. Botão oval a clavado, no sul forma opérculos hemisféricos e subglaucos, no norte apresenta forma cônica e dificilmente glauco. Fruto hemisférico a campanulado, subglauco quando imaturo; disco estreito, levemente convexo ou mais ou menos iguais, 3-4 valvas.

A madeira é moderadamente dura, adequada para uso em locais protegidos (HALL \& BROOKER, 1973).

O Eucalyptus benthamii Maiden et Cambage foi introduzido no Brasil pela Embrapa/Florestas, tendo em vista que espécies do gênero têm sido usadas em extensos programas de reflorestamento e o mesmo apresenta boa resistência a geadas e grande probabilidade de ser utilizado para fins industriais, sendo necessários maiores estudos sobre suas características anatômicas e tecnológicas.

O presente trabalho tem por objetivo verificar as variações dos elementos constituintes do xilema secundário, além de considerar possíveis tendências de variações existentes dentro das diferentes árvores desta espécie.

\section{MATERIAIS E MÉTODOS}

O material estudado compreendeu 15 árvores provenientes de um povoamento com 7 anos de idade da Embrapa, localizado em Colombo-Paraná, com espaçamento de 3x3 m.

As mesmas foram coletadas aleatoriamente, abrangendo todas as classes de dominância, sendo retirados discos no DAP, $0 \%, 25 \%, 50 \%, 75 \%$ e $100 \%$ da altura comercial (diâmetro de 6 $\mathrm{cm})$, totalizando 6 discos por árvore.

As amostras de madeira destinadas à obtenção das seções histológicas do xilema foram retiradas aleatoriamente dentro dos discos e orientadas para a obtenção de cortes nos planos transversal, longitudinal radial e longitudinal tangencial. Após o amolecimento por fervura em água, procedeu-se o seccionamento em micrótomo de deslizamento modelo Spencer AO $\mathrm{n}^{\circ} 860$, com espessura variando de 14 a 24 micrômetros. As seções foram tingidas pelo método de tripla coloração, com acridina vermelha, crisoidina e azul de astra, sendo posteriormente desidratadas em série alcoólica ascendente, colocadas em xilol e montadas em lâminas permanentes com Entellan.

A maceração dos tecidos componentes da madeira foi efetuada pelo método de Jefrey que 
consiste no desmembramento através de uma solução aquosa de ácido nítrico e ácido crômico, ambos a 10\%, na proporção de 1:1. Utilizou-se safranina como corante e o processo de desidratação e montagem empregados foram os mesmos descritos anteriormente.

Tanto para as descrições microscópicas como para as mensurações dos elementos celulares individuais seguiu-se as normas da ABNT, com alterações introduzidas por MUÑIZ (1991).

Os dados quantitativos dos caracteres anatômicos obtidos das medições foram processados em computador e obteve-se valores médios, máximos, mínimos e desvio padrão para cada característica estrutural.

Para a tomada das fotomicrografias, foi utilizado um fotomicroscópio Carl Zeiss. O filme empregado foi Kodak-Panatomic, Asa 32 e as ampliações feitas em papel fotográfico Kodabromid F3 brilhante. Também foi realizada microscopia eletrônica, utilizando filme Vericrhome 120, fixador e papel revelador da Kodak.

\section{RESULTADOS E DISCUSSÃO}

\section{Descrição da madeira}

Características gerais: madeira moderadamente dura (densidade básica de $0,47 \mathrm{~g} / \mathrm{cm}^{3}$ ); cerne e alburno distintos, cerne de cor marrom avermelhada e alburno amarelo rosado; textura fina a média, grã irregular, cheiro e gosto imperceptíveis; superfície levemente brilhante em luz adequada.

Anéis de Crescimento: indistintos

Vasos: visíveis a olho nu, solitários, arredondados, porosidade difusa, arranjo dos poros em diagonal (Figura 2A). Diâmetro tangencial variando de 30-240 $\mu \mathrm{m}$, média de $131 \mu \mathrm{m}(\mathrm{s}=41,21)$, espessura da parede em torno de $10 \mu \mathrm{m}$. Comprimento dos elementos vasculares de 120 a $650 \mu \mathrm{m}$, média de $326 \mu \mathrm{m}(\mathrm{s}=67,27)$, apêndices presentes em ambas as extremidades, em sua maioria. Poros $/ \mathrm{mm}^{2}$ de 5 a 21 , média de 13; placa de perfuração simples; tilos presentes mas não abundantes (Figura 3A, B). Pontoações intervasculares areoladas, alternas (Figura 3D). Pontoações raiovasculares simples, arredondadas, alternas, pequenas, variando de 2,5 a $5 \mu \mathrm{m}$ de diâmetro tangencial (Figura 3C). Pontoações parênquimo-vasculares semelhantes às raio vasculares.

Parênquima axial: distinto só sob lente, paratraqueal vasicêntrico e vasicêntrico confluente.

Parênquima radial: raios homogêneos, formados apenas por células procumbentes, unisseriados, às vezes localmente bisseriados (Figura 2C), altura variando de 50 a $420 \mu \mathrm{m}$, média de $195 \mu \mathrm{m}(\mathrm{s}=69,40) ; 7-18 \mathrm{raios} / \mathrm{mm}$, média de 12 . Óleo resina às vezes presente (Figura $2 \mathrm{~B})$.

Fibras: libriformes, não septadas, muito curtas a curtas, com comprimento variando de 500$1700 \mu \mathrm{m}$, média de $818 \mu \mathrm{m}(\mathrm{s}=113,40)$; paredes delgadas, espessura em torno de $2,5 \mu \mathrm{m}$, existindo de 1 a $5 \mu \mathrm{m}$ (Figura 2D).

Máculas medulares ocasionalmente presentes (Figura 2A).

Ciência Florestal, v.8, n.1, 1998 


\section{Análise da estrutura anatômica}

Os principais caracteres anatômicos do xilema secundário do Eucalyptus benthamii são comuns nas Mirtáceas e atestam alto grau de evolução. Dentre estes, incluem-se elementos vasculares curtos, placas de perfuração simples, parênquima axial paratraqueal, raios homogêneos e fibras libriformes.

O arranjo diagonal dos poros é uma característica do gênero Eucalyptus.

A porcentagem encontrada para os tecidos constituintes do xilema secundário mostra a grande porcentagem de fibras existentes, assim como apresenta-se dentro dos valores existentes em outros gêneros e espécies da família Myrtaceae. Os valores para a espécie em estudo são apresentados na Figura 1.

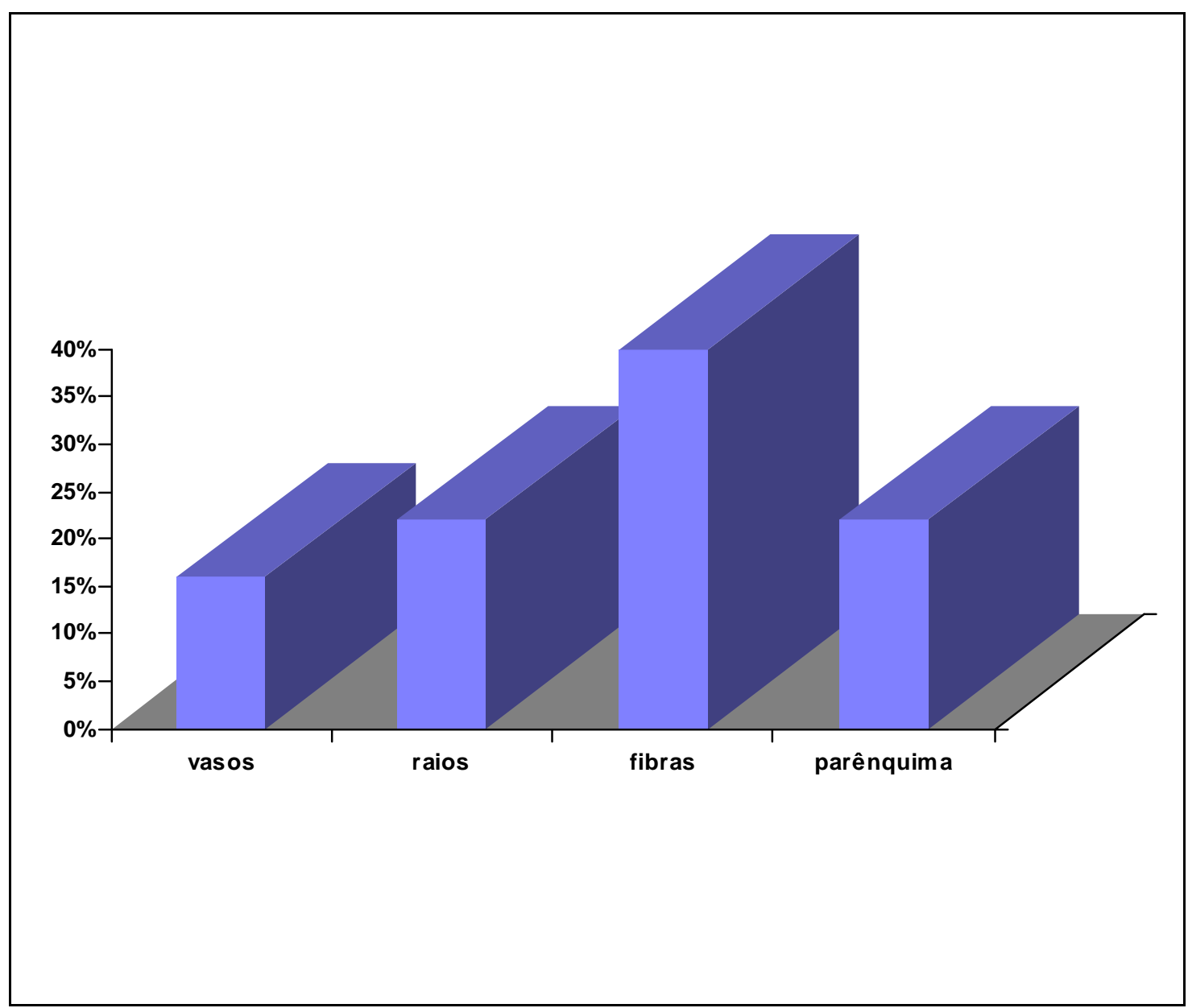

FIGURA 1: Porcentagem dos elementos constituintes do xilema secundário de Eucalyptus benthamii. 

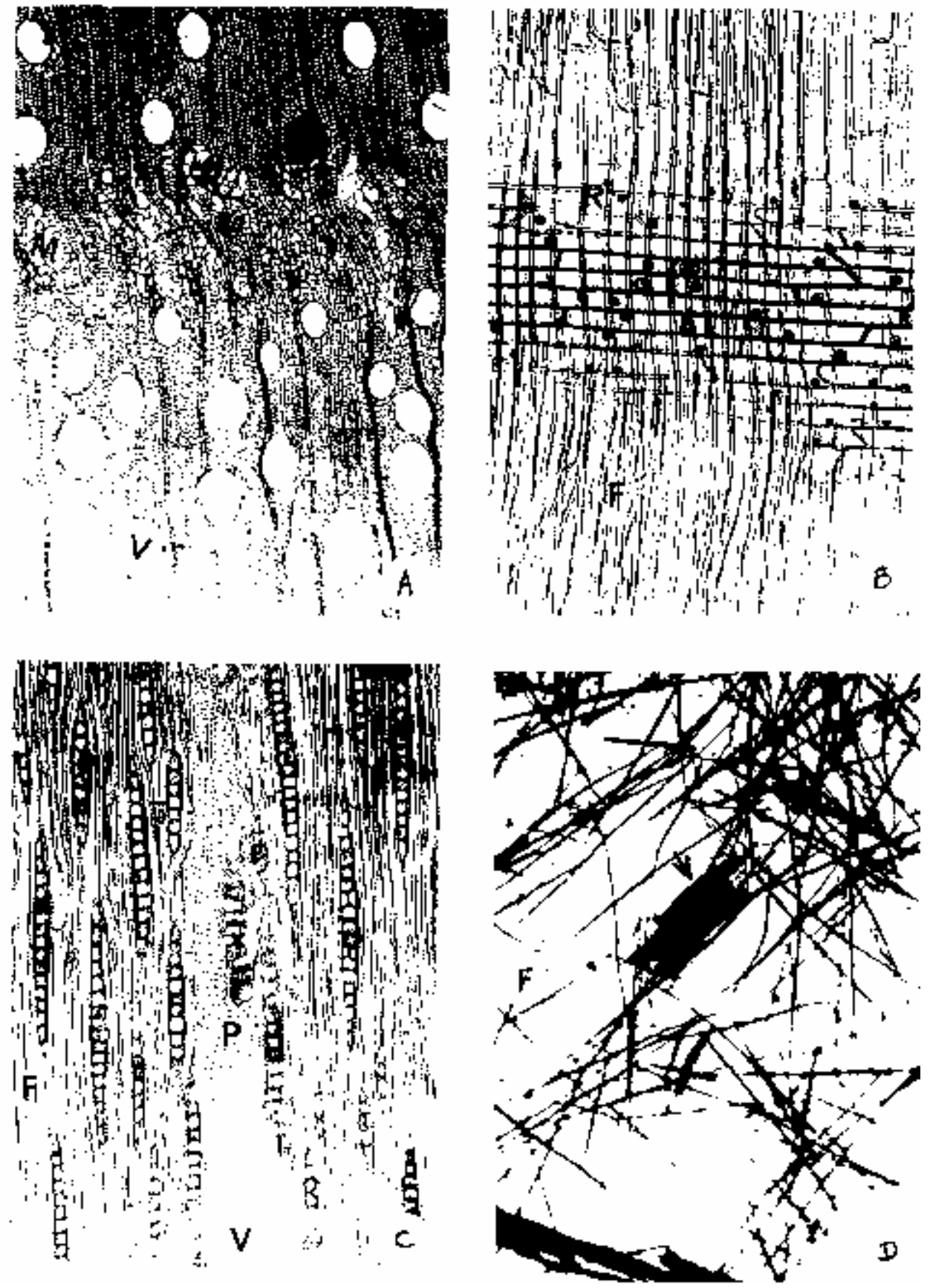

FIGURA 2: Fotomicrografias da madeira A) Seção transversal: mácula medular M), poros em disposição tangencial (aumento 50x). B) Seção radial: raios homogêneos (R) com óleo resina e fibras (F) (aumento 400x). C) Seção tangencial: raios uni e localmente bisseriados $(\mathrm{R})$, pontoações parênquimo-vasculares $(\mathrm{P})$, vaso $(\mathrm{V})$ e fibras $(\mathrm{F})$ (aumento 200x) D) Macerado: fibras (F) e elemento de vaso com apêndices (aumento 50x).

Ciência Florestal, v.8, n.1, 1998 

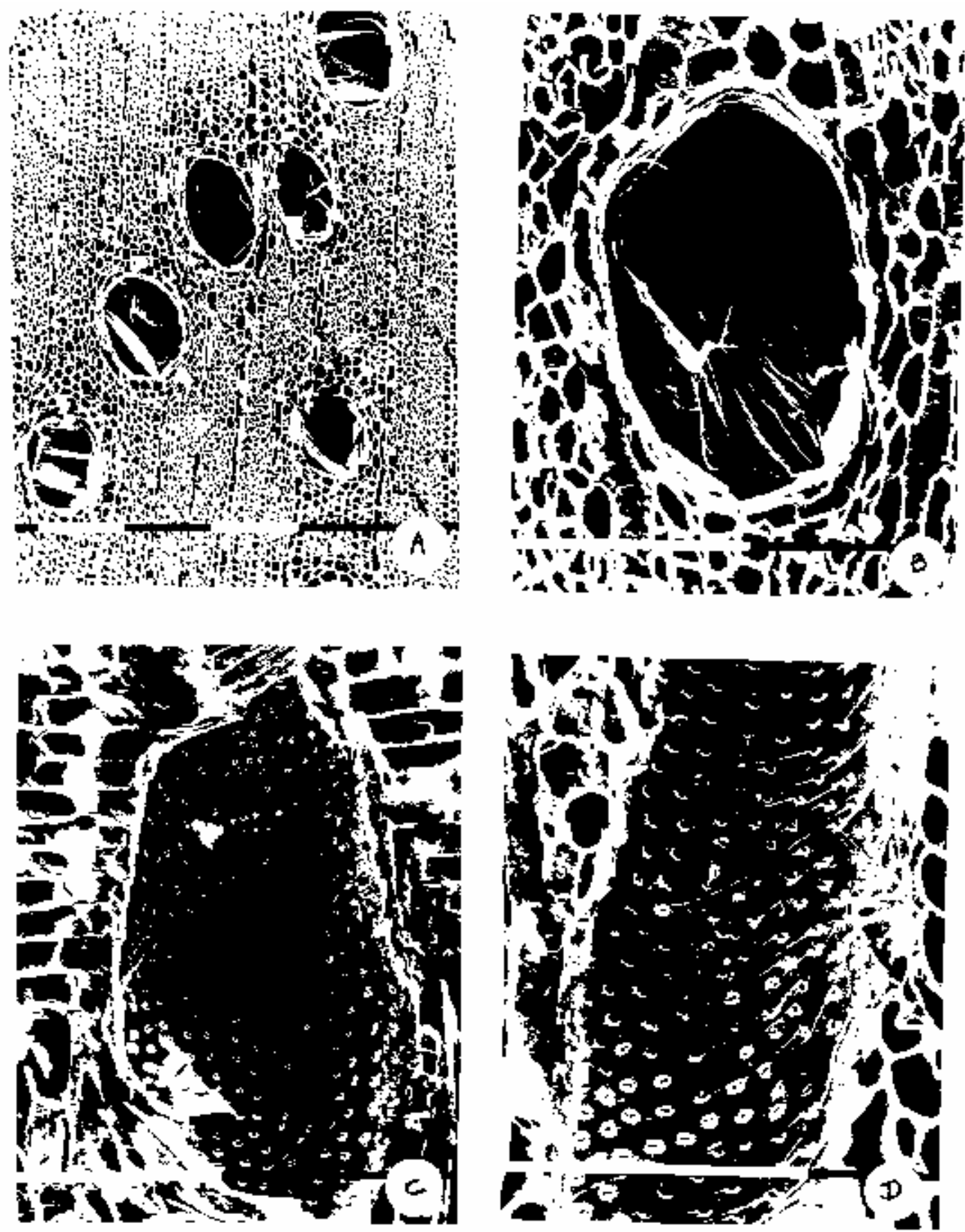

FIGURA 3: Fotografias da madeira em microscópio eletrônico: A) Seção transversal: poros com tilos (aumento 120 x). B) Seção transversal: detalhe de um tilo (aumento 462x). C) Seção radial: pontoações raio-vasculares (aumento 388x). D) Seção tangencial: pontoações intervasculares (aumento 549x). 


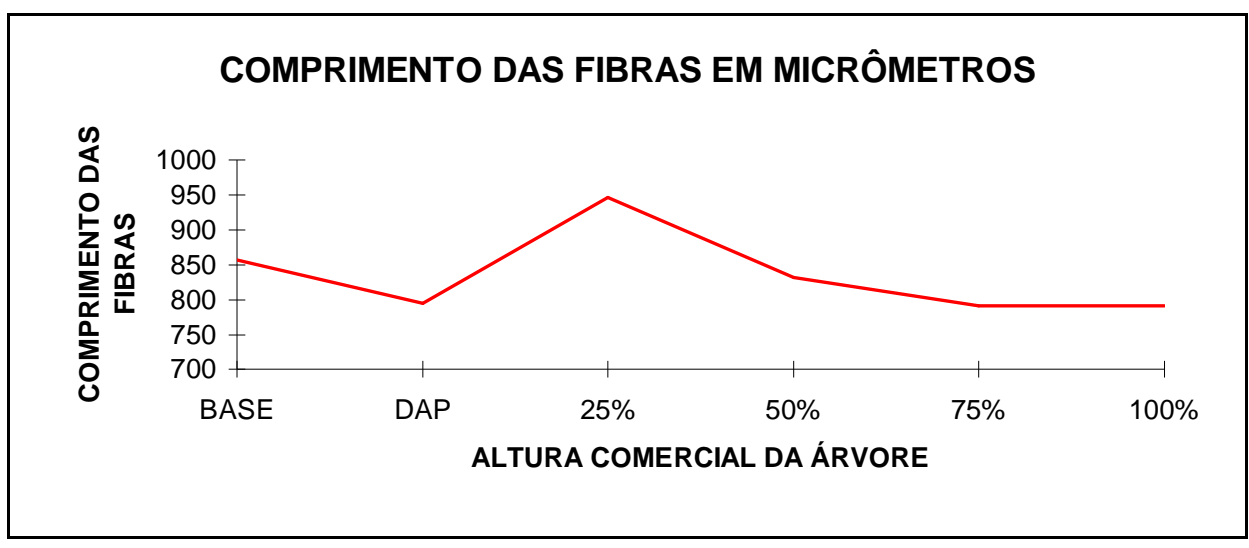

FIGURA 4: Variação do comprimento das fibras de acordo com a altura na árvore.

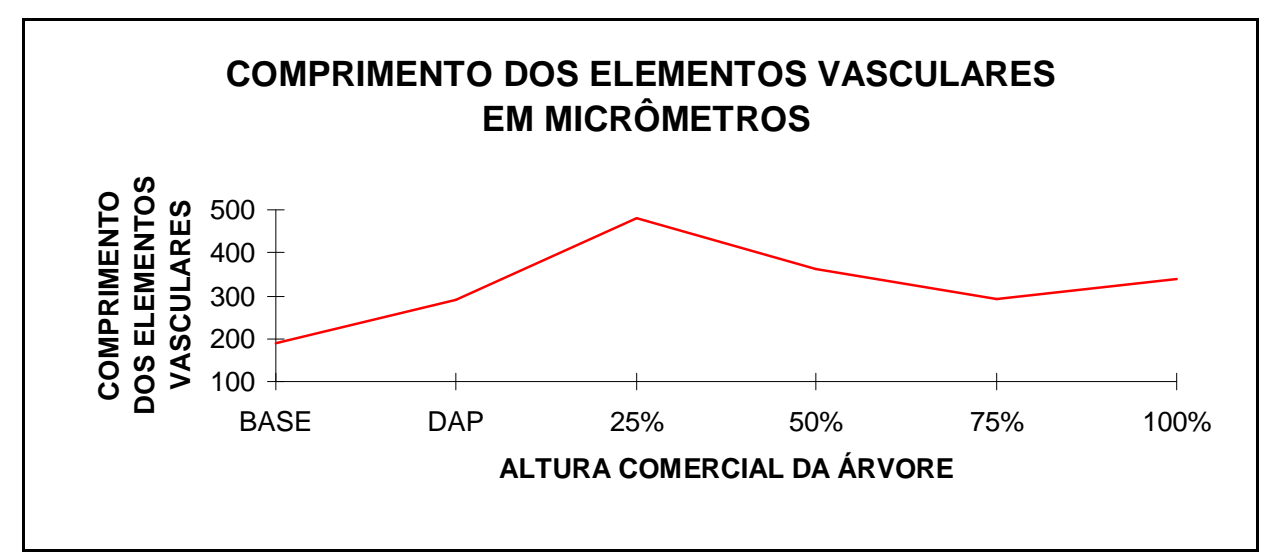

FIGURA 5: Variação do comprimento dos elementos vasculares de acordo com a altura da árvore.

As Figuras 4 e 5 mostram a variação existente entre as fibras e os elementos vasculares dentro de um indivíduo, a qual apresenta um pico entre o DAP e 50\% da altura comercial da árvore, indicando o período de maior crescimento e instabilidade dos elementos constituintes.

A Tabela 1 apresenta a densidade básica de alguns eucaliptos, determinada pela norma TAPPI 258-OM-85 (peso de madeira seca/volume verde). O valor de densidade básica encontrado TABELA 1: Densidade da madeira de eucalipto.

\begin{tabular}{lc}
\hline \multicolumn{1}{c|}{ Espécie } & Densidade Básica $\left(\mathrm{kg} / \mathrm{dm}^{3}\right)$ \\
\hline E. tereticornis & 0,514 \\
E. camaldulensis & 0,447 \\
E. saligna & 0,484 \\
E.viminalis & 0,507 \\
E.grandis & 0,409 \\
E. dunnii & 0,550 \\
\hline
\end{tabular}

Fonte: REPETTI, 1987 citado por INTA (1995). 
para o Eucalyptus benthamii ficou em $0,47 \mathrm{~g} / \mathrm{cm}^{3}$, ficando o mesmo numa faixa intermediária de espécies já conhecidas.

\section{CONCLUSÕES}

A estrutura anatômica da madeira de Eucalyptus benthamii permite as seguintes conclusões:

- a madeira apresenta uma estrutura anatômica evoluída, uma vez que possui elementos vasculares curtos, com placa de perfuração simples; raios homogêneos, estreitos e de altura média;

- a presença de máculas ocasionais indica que algumas árvores do povoamento sofreram danos físicos, provavelmente ocasionados por intempéries ou pelo homem;

- a variação dos elementos constituintes dentro de uma mesma árvore foi comprovada, ocorrendo um pico no período de maior crescimento, tendendo à estabilização à medida em que a árvore envelhece;

- comparando-se a densidade do Eucalyptus benthamii com outras espécies, o mesmo talvez apresente propriedades físicas e mecânicas semelhantes ao Eucalyptus grandis;

- os problemas de secagem e rachaduras também serão semelhantes.

- as conclusões acima só poderão ser confirmadas com ensaios práticos de anisotropia e testes físico mecânicos, mas a estrutura anatômica fornece informações importantes sobre seu possível comportamento.

- embora bem adaptada, um manejo adequado do povoamento é indicado para a obtenção de madeira de melhor qualidade.

\section{AGRADECIMENTOS}

Agradecemos à Embrapa/CNPF pelo fornecimento da madeira da espécie em estudo. Este trabalho faz parte do Projeto Caracterização da Madeira de Algumas Espécies Florestais realizado pela mesma.

\section{REFERÊNCIAS BIBLIOGRÁFICAS}

ANDRADE, E.N. O eucalipto. São Paulo: Companhia Paulista de Estradas de Ferro,1961. 667 p.

COSTA, E.M. A madeira do eucalipto na indústria moveleira. Curitiba: Anais do IV SEMADER, 1996.

COZZO, D. Eucalyptus y eucaliptotecnia. Buenos Aires: El Ateneo, 1955. 393 p. 
FOREST TREES SERIES $\mathrm{N}^{\circ}$ 57, DEPARTMENT OF NATIONAL DEVELOPMENT FORESTRY AND TIMBER BUREAU, NORMAL HALL E IAN BROOKER, CAMBERRA 1973.

INTA Manual para productores de eucaliptos de la Mesopotamia Argentina. Argentina : Grupo Forestal, EEA, 1995. 162 p.

JOLY,A.B BOTÂNICA - Introdução à taxonomia vegetal. São Paulo: Ed. Nacional, 1985. 777 p.

METCALFE, C.R. \& CHALK, L. Anatomy of the dicotyledons - Vol 1. Oxford, 1965. 724 p.

MUÑIZ, G.I.B. \& CORADIN, V.R. Normas de procedimentos em estudos de anatomia da madeira: I-Angiospermae, II Gimnospermae. Brasília: Laboratório de Produtos Florestais, Série Técnica 15, 1991.

RECORD, S.J. \& HESS, R.W. Timbers of the New World. New York: Arno Press, 1972. 640 p.

STAPE, J.L. Manejo de Eucalyptus spp. para desdobro frente aos avanços silviculturais de produção. Curitiba: Anais do IV SEMADER,1996.

VIANA, L.O. - Experiência do SENAI/CETMAN com secagem de eucalipto. Curitiba: Anais do IV SEMADER, 1996. 